\title{
Fine Flame Structure and Combustion Mechanism of Lean Turbulent Premixed Flames*
}

\author{
Takeo TAKAHASHI**, Masashi KATSUKI*** \\ and Yukio MIZUTANI***
}

\begin{abstract}
We observed the interaction between turbulence and combustion near the lean flammability limit of a premixed flame supported by a hot burnt-gas jet, and elucidated the detailed structure of flames varying with the Damkohler number. A typical wrinkled laminar flame appeared when the equivalence fuel-to-air ratio of the mixture was 0.6 , whereas, for an equivalence ratio below the lean flammability limit (e.g., $\Phi_{m}$ $=0.4$ ), a structure which resembled a distributed reaction zone was observed. The latter showed features similar to those of the ordinary distributed reaction zone flame, which was observed in a strongly turbulent shear layer, in many aspects of the observed statistics of fluctuating properties, such as temperature, ion current, and radical chemiluminescence.
\end{abstract}

Key Words: Combustion, Turbulent Combustion, Premixed Combustion, Flame Structure

\section{Introduction}

Most turbulent flames consist of laminar flamelets where the combustion reaction is very rapid as compared with turbulent processes, and the reaction is completed within a very thin laminar interface. A steady "distributed reaction zone" is rarely observed, except in a strongly turbulent shear layer ${ }^{(1)-(3)}$ or in an opposing jet ${ }^{(4)}$. This is because a distributed reaction zone is a combustion regime near extinction, and blowoff due to stretching or cooling by mixing is apt to occur.

In our previous experiments ${ }^{(1),(2)}$ we observed the flame structure in the shear layer between a hot pilot jet and a reactant stream, and found that helium, added as a tracer in the hot pilot jet, diffused into the unburned reactant stream beyond the combustion zone of the distributed reaction regime. It was pos-

* Received 21st August, 1992. Paper No. 91-1179 A

** Presently, Staff College, Japan Ground Self-Defense Force, 5-1 Motomura, Ichigaya, Shinjuku, Tokyo 162, Japan

*** Department of Mechanical Engineering, Osaka University, 2-1 Yamada-oka, Suita, Osaka 565, Japan sibly due to the local extinction caused by extremely intense turbulence. This was supported by the fact that the Damkohler number based on the Taylor microscale was estimated to be far smaller than unity.

The Damkohler number is defined as the ratio of the characteristic time of turbulent mixing to that of chemical reaction $^{(5)}$. The distributed reaction zone can be realized by reducing the characteristic mixing time, as in the previous examples. It is quite interesting to see how the flame structure changes when the characteristic reaction time is elongated by decreasing the mixture equivalence ratio. Attempts to reduce the Damkohler number by elongating the characteristic chemical time have been made for turbulent nonpremixed flames by Masri and others ${ }^{(6)-(8)}$ and Mungal and $\mathrm{co}^{-}$-workers ${ }^{(9)-(11)}$. However, no such attempt has been made for turbulent premixed flames.

In the present study, we stabilized a weak-reaction flame supported by a pilot burner placed at the center of the two-dimensional shear layer formed in a reactant flow in a square-duct near the lean flammable limit. We first observed the detailed structure of the lean turbulent flames and discussed the relationship between fine flame structure and flame propaga- 
tion. Then, in order to elucidate the interaction between the turbulence and reaction for small Damkohler number flames, we examined the similarity between two low Damkohler number flames established by reducing the mixture equivalence ratio and by increasing the turbulence intensity of the reactant flow.

\section{Experimental Apparatus and Procedure}

Figure 1 shows the burner geometry. The observation section was a transparent square duct of 50 $\mathrm{mm} \times 50 \mathrm{~mm}$ cross section and $300 \mathrm{~mm}$ length to allow optical measurements. In order to form an almost uniform shear flow, a matrix of stainless steel tubes of $3.06 \mathrm{~mm}$ o.d. and $0.21 \mathrm{~mm}$ thickness was installed at the bottom of the section along with wire gauze having a nonuniform mesh pattern located below the matrix. The matrix had an archlike side view to produce a uniform velocity gradient across the duct. Three sheets of wire gauze were placed above and below the matrix to damp the turbulence or to produce the desired velocity profile.

A pilot burner associated with a recess of $6.5 \mathrm{~mm}$ o.d. and $0.5 \mathrm{~mm}$ thickness at the port of the burner tube, $3.06 \mathrm{~mm}$ o.d. and $0.21 \mathrm{~mm}$ thickness, was placed on the central axis of the duct $50 \mathrm{~mm}$ above the top of the matrix.

Constant-temperature anemometry was applied in the measurement of noncombusting flows. Figure 2 shows the profiles of the time-averaged velocity $\bar{U}$ and its RMS of fluctuation $u$ ' measured in the cross

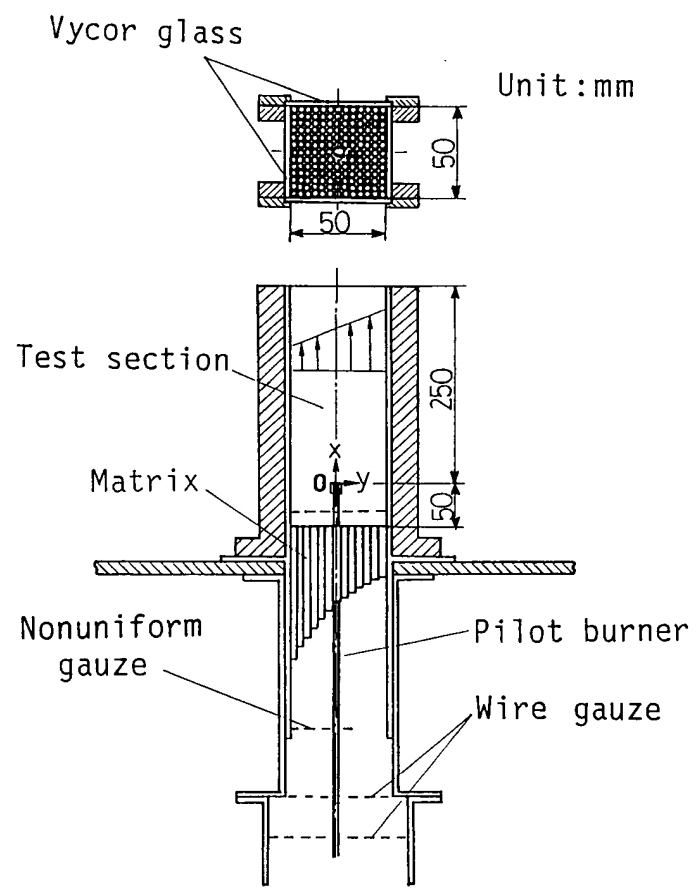

Fig. 1 Burner geometry section at $x=50 \mathrm{~mm} . \bar{U}$ varies from $4.7 \mathrm{~m} / \mathrm{s}$ to 15.8 $\mathrm{m} / \mathrm{s}$ with an almost uniform velocity gradient. All the measurements were carried out under this flow condition with the variation in the mixture equivalence ratio $\Phi_{m}$.

The fuel premixed with air was a city gas of natural gas origin $(88 \%$ methane by vol. with a high calorific value of $37.7 \mathrm{MJ} / \mathrm{m}^{3}$ ). The pilot burner was fed a stoichiometric hydrogen-air mixture at a rate of $20 \mathrm{~cm}^{3} / \mathrm{s}$.

A conventional schlieren photography arrangement with a light source of $2 \mu \mathrm{s}$ flash duration was used to observe the flow. The temperature was measured using a $\mathrm{Pt} / \mathrm{Pt}-13 \% \mathrm{Rh}$ thermocouple of $25 \mu \mathrm{m}$ wire diameter with a thermal inertia compensating circuit $^{(12)}$. The ion current was detected using an electrostatic probe with a sensing needle of $0.1 \mathrm{~mm}$ diameter and $0.5 \mathrm{~mm}$ length kept at a voltage of $-18 \mathrm{~V}$.

The chemiluminescence of $\mathrm{C}_{2}, \mathrm{CH}$ and $\mathrm{OH}$ radicals was monitored simultaneously using the optical system illustrated in Fig. 3, which consisted of a quartz lens, two dichroic mirrors, and three interference filter-photomultiplier combinations. The peak wavelength $\lambda_{p}$ and half-height width $\Delta \lambda_{p}$ of the interference filters were, respectively, $516.4 \mathrm{~nm}$ and $1.0 \mathrm{~nm}$ for $\mathrm{C}_{2}$ radicals, $430.5 \mathrm{~nm}$ and $0.9 \mathrm{~nm}$ for $\mathrm{CH}$ radicals and $308.5 \mathrm{~nm}$ and $17.0 \mathrm{~nm}$ for $\mathrm{OH}$ radicals. The waist diameter of the measuring volume was restricted to 2 $\mathrm{mm}$ by pin holes. These signals were digitized by an A/D converter and analyzed statistically or spectrally on a personal computer or a signal analyzer. All the

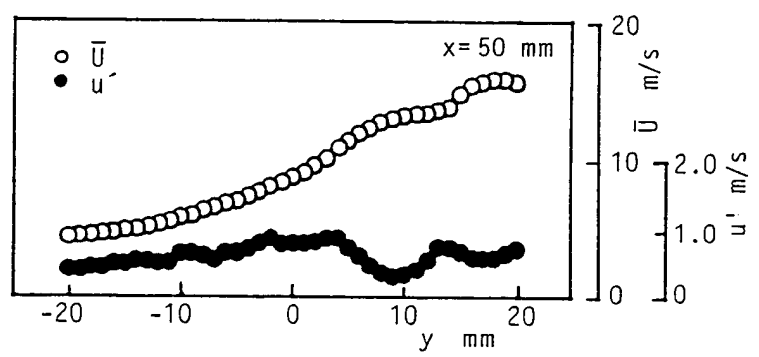

Fig. 2 Profiles of time-averaged velocity and its fluctuating component (nonreacting)

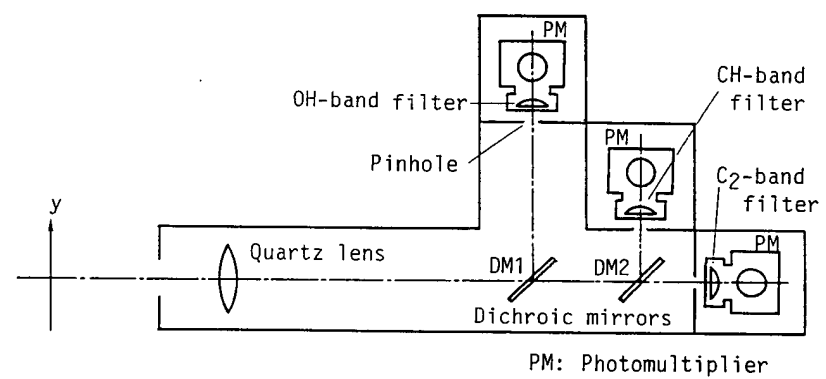

Fig. 3 Optical system for chemiluminescence monitoring 
measurements were carried out in the $x-y$ plane shown in Fig. 1, and the monitoring points were indicated by the $x-y$ coordinates with the origin at the center of the pilot burner port.

\section{Results and Discussion}

\subsection{Schlieren images}

Figure 4 shows the schlieren photographs taken with the equivalence ratio $\Phi_{m}$ varied stepwise by 0.1 from 0 to 0.6. In Fig. 4 (a) for $\Phi_{m}=0$, a mixing layer between air and hot burnt-gas jet about $10 \mathrm{~mm}$ long, originating from the pilot flame, is visualized. Similar images are observed in both Figs. 4(b) and (c), although a slight amount of fuel was added to the main stream. In Fig. 4 ( g ) for $\Phi_{m}=0.6$, propagating flames are clearly seen spreading away from the pilot jet. The apparent flame angle is wider on the lowvelocity side (left-hand side), and the flames on both sides appear to have a structure close to that of a "wrinkled laminar flame" or "laminar flamelets."
It is interesting that, in Figs. 4 ( d ) - ( f ) for $\Phi_{m}=$ $0.3-0.5$ which are slightly below the lean flammability limit, the high-temperature fluids appear to spread into the cold stream and the image contour becomes clearer. This seems to imply that some fraction of the cold combustible mixture exhibits exothermic reaction due to the heat of the entrained hot burnt gas. This may not be a self-propagating flame but a flame with a slow reaction rate, hence "a flame of small Damkohler number." This flame has lower flame temperature and longer characteristic reaction time compared with the ordinary propagating one in Fig. $4(\mathrm{~g})$, which makes measurements easier. Therefore, the detailed structure of the flame and its correlation with flame propagation were examined with respect to turbulent characteristics.

\section{2 Temperature signals}

Figure 5 shows the profiles of time-averaged temperature $\bar{T}$ and RMS values of fluctuating temperatures $t$ ' for $\Phi_{m}=0,0.4,0.5$ and 0.6 . The equiva-

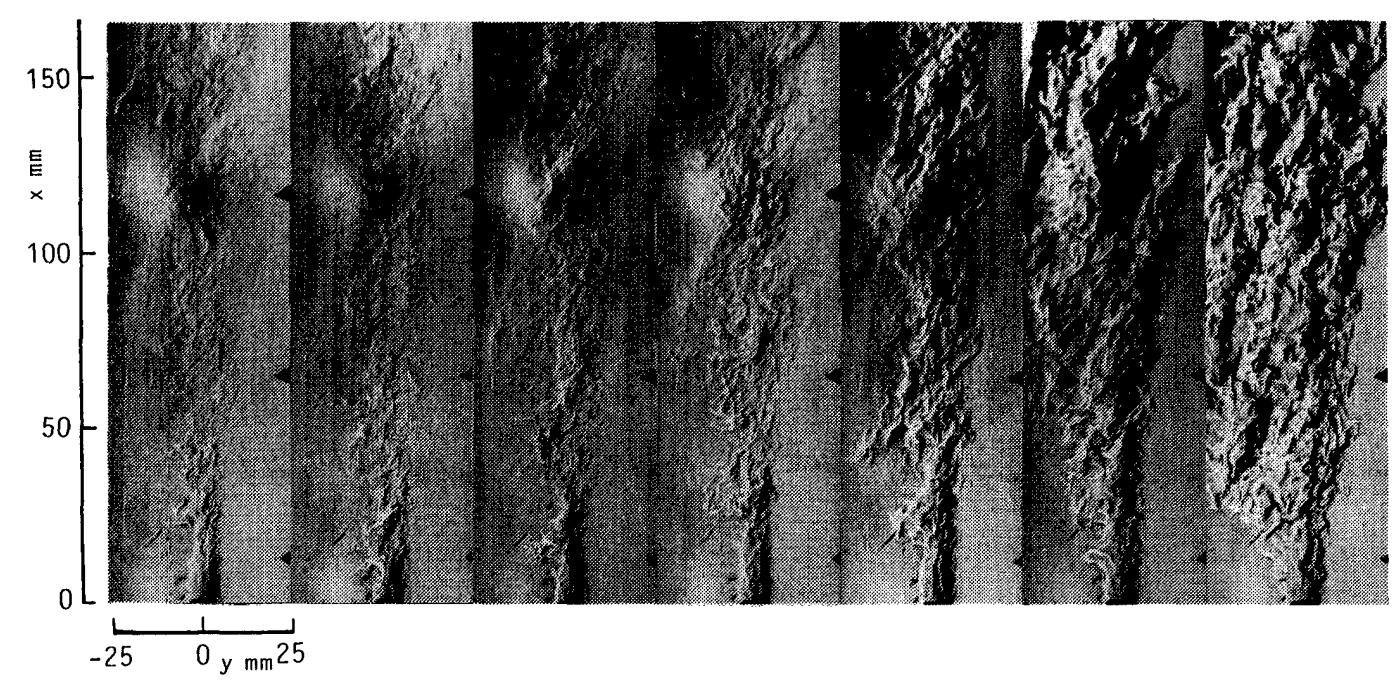
(a) $\phi_{m}=0$
(b) $\phi_{\mathrm{m}}=0.1$
(c) $\phi_{\mathrm{m}}=0.2$
(d) $\phi_{m}=0.3$
(e) $\Phi_{m}=0.4$
(f) $\phi_{m}=0.5$
(g) $\phi_{m}=0.6$

Fig. 4 Schlieren images of hot burnt-gas stream with/without flame

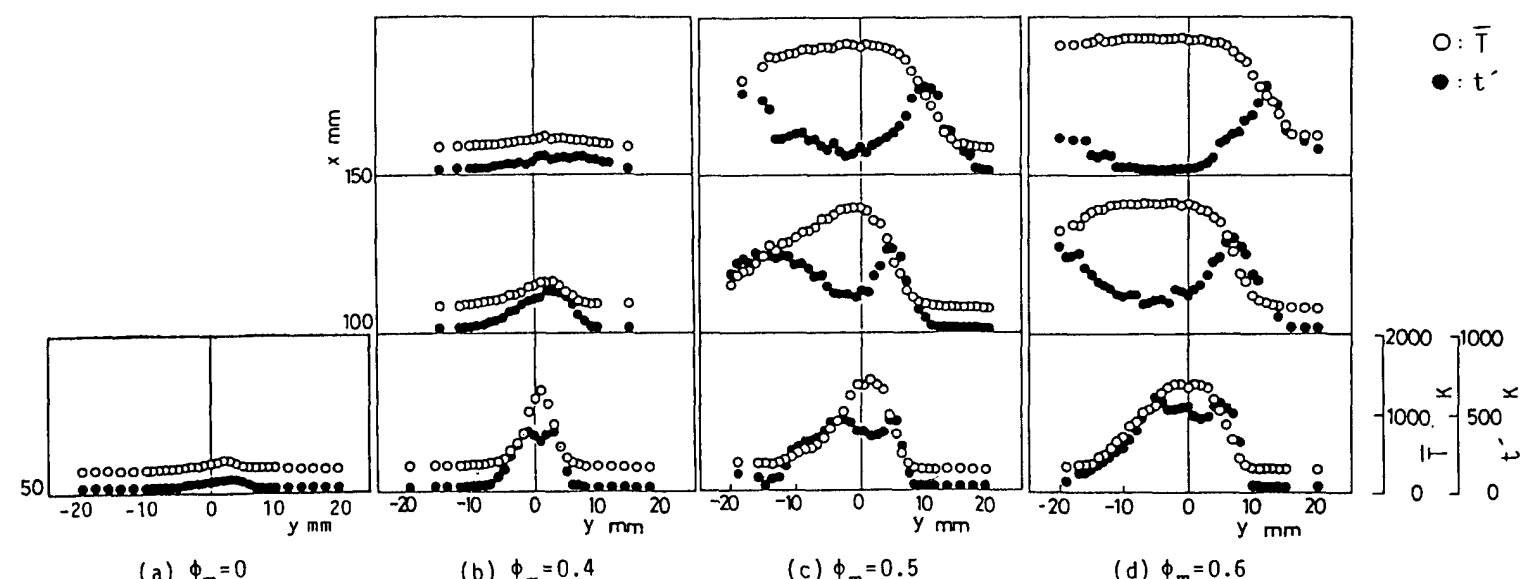

(a) $\phi_{m}=0$

(b) $\phi_{m}=0.4$

(c) $\phi_{\mathrm{m}}=0.5$

(d) $\phi_{m}=0.6$

Fig. 5 Profiles of time-averaged temperature and its fluctuating component 
lence ratio of the pilot flame was reduced to 0.6 in case of $\Phi_{m}=0.6$ to prevent the thermocouple from melting. For $\Phi_{m}=0$, no data were taken in the cross sections at $x=100 \mathrm{~mm}$ and $150 \mathrm{~mm}$, since the temperature was almost uniform there. The hot burnt gas was almost diffused out before reaching the cross section at $x=50$ $\mathrm{mm}$, and the temperature rise due to the mixed hot gas was not marked. It is presumed, therefore, that the temperature profiles for mixtures leaner than the flammability limit would be the same if chemical reaction did not occur.

In Fig. 5( b ) for $\Phi_{m}=0.4$, however, $\bar{T}$ and $t$ ' show considerably high peaks around the central axis in the cross section at $x=50 \mathrm{~mm}$. The peak height is $1300 \mathrm{~K}$ for $\bar{T}$, which is almost equal to the adiabatic flame temperature, and more than $300 \mathrm{~K}$ for $t$ ', although the profiles of $\bar{T}$ and $t^{\prime}$ at $x=150 \mathrm{~mm}$ are similar to those for the mixing case of Fig. 5(a). This implies that a certain type of flame has been established in the neighborhood of the pilot jet, which tends to be extinguished downstream before noticeably spreading by propagation.

The high-temperature region greatly expands in Fig. 5(d) for $\Phi_{m}=0.6$, especially in the low-velocity side, and the peak value of $\bar{T}$ is not reduced downstream with the progress of mixing. These suggest that a self-propagating flame has been retained across the reactant flow without extinction. The $t$ ' value has its peaks at the positions corresponding to the maximum gradient in the $\bar{T}$ profile. It is seen that the valley between $t$ ' peaks is deepened and the region of fully burnt gas expands downstream.

The features in Fig. 5(c) for $\Phi_{m}=0.5$ are the interactions of the two described above. The onset of the self-propagating flame obviously starts around this mixture strength, and decaying tendency is not seen as far away as $x=150 \mathrm{~mm}$. It is of interest to examine the detailed flame structures in this transition region and the propagating mechanism. Hence, we will focus attention on this flame.

\section{3 Probability density functions of temperature}

The probability density functions (PDF's) of fluctuating temperatures are shown in Figs. 6 to 8. The shadowed portion in the figures indicates the probability of the temperatures exceeding the "critical flame temperature" for a propagating premixed methaneair flame, $1483 \mathrm{~K}$, obtained through the opposed-flame experiments $^{(13)}$. In Fig. 6 for $\Phi_{m}=0$, the PDF of temperature is almost Gaussian around the axis, which is typical for a simple mixing process, and the maximum temperature is comparatively low.

In Fig. 7 for $\Phi_{m}=0.4$, the PDF of temperature is extended toward high temperature, which indicates the occurrence of exothermic reaction. The shadowed parts in the $x=50 \mathrm{~mm}$ cross section indicate the existence of a propagating flame at the monitoring point. Adding to the original low-temperature peak, a new high-temperature peak appears in the PDF at $x=50$ $\mathrm{mm}$ and $y=3 \mathrm{~mm}$, as presented in Fig. 7 ( a ), probably due to a propagating flame, and the valley between the two peaks shows some high probabilities of intermediate temperatures corresponding to the slow reaction processes. This type of PDF resembles the one observed in a "distributed reaction zone flame" in intense turbulence of small scale ${ }^{(2)}$. Although this result does not always assure that the present flame is of the same structure as the distributed reaction zone, the possibility still remains that they are the same because the probability of temperatures exceeding the critical flame temperature exists.

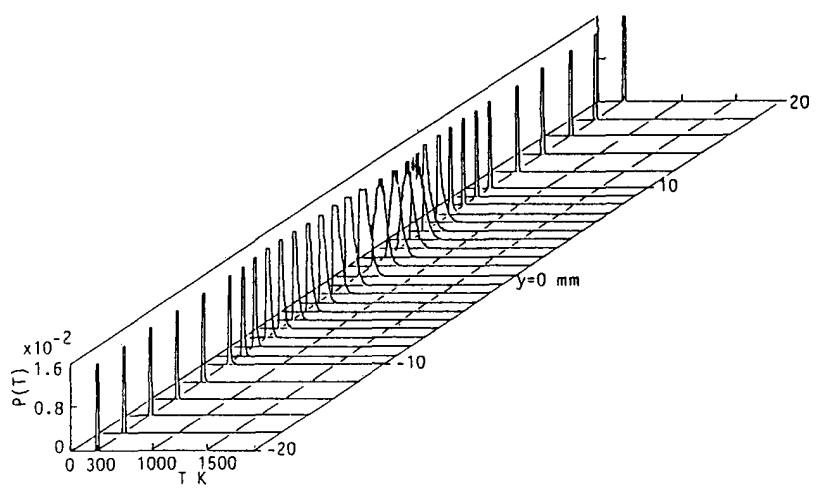

Fig. 6 Probability density functions of fluctuating temperature for $\Phi_{m}=0$ at $x=50 \mathrm{~mm}$

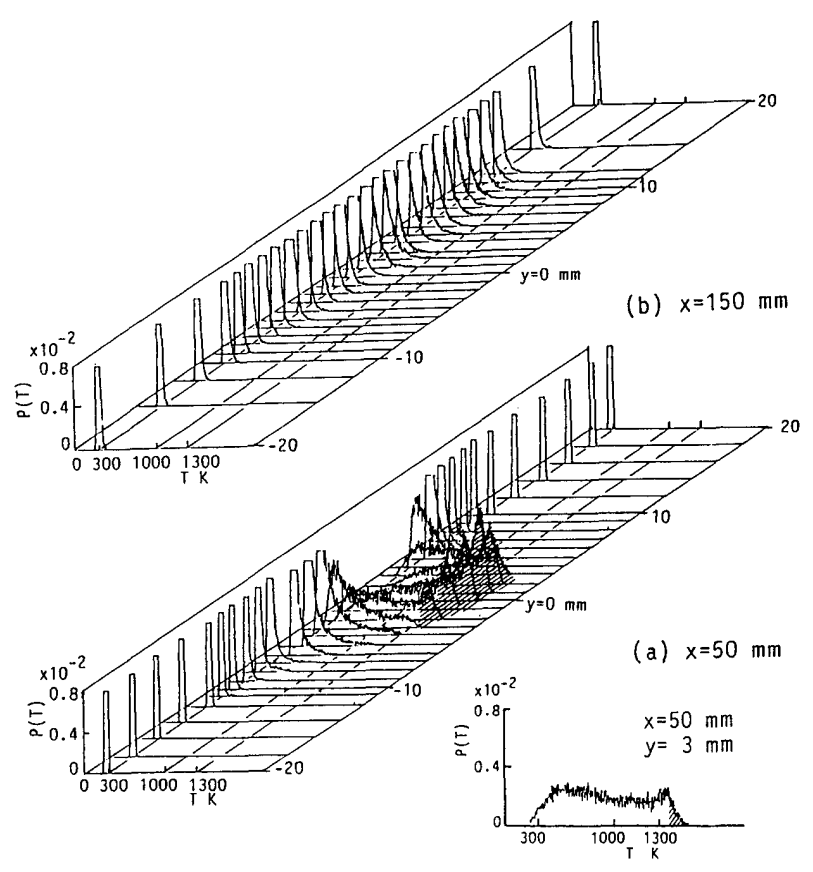

Fig. 7 Probability density functions of fluctuating temperature for $\Phi_{m}=0.4$ 
In Fig. 8 for $\Phi_{m}=0.6$, the low- and high-temperature peaks are significant, whereas the probabilities of intermediate temperatures become lower downstream. This implies that the flames have changed their structure into that of the wrinkled laminar flame.

Here, we discuss again the plateaulike PDF pattern observed at $x=50 \mathrm{~mm}$ of $\Phi_{m}=0.4$ (Fig. 7(a)). Not only is the shape of this PDF different from the one in a nonreacting mixing layer, but higher temperatures due to exothermic reactions are also observed. Therefore, the shape of the PDF is reasonably ascribed to the influence of low Damkohler number, as was the case in the distributed reaction $z o n e^{(2)}$. From a different point of view, however, the interpretation that the two structures are the same may not be possible because the reaction in a lean mixture below the flammability limit depends upon the heat transfer due to mixing with the high-temperature pilot gases.

If a propagating flame is included in the reaction zone of the lean flame of $\Phi_{m}=0.4$, reactions must occur in the limited thin interface of flamelets. Hence,

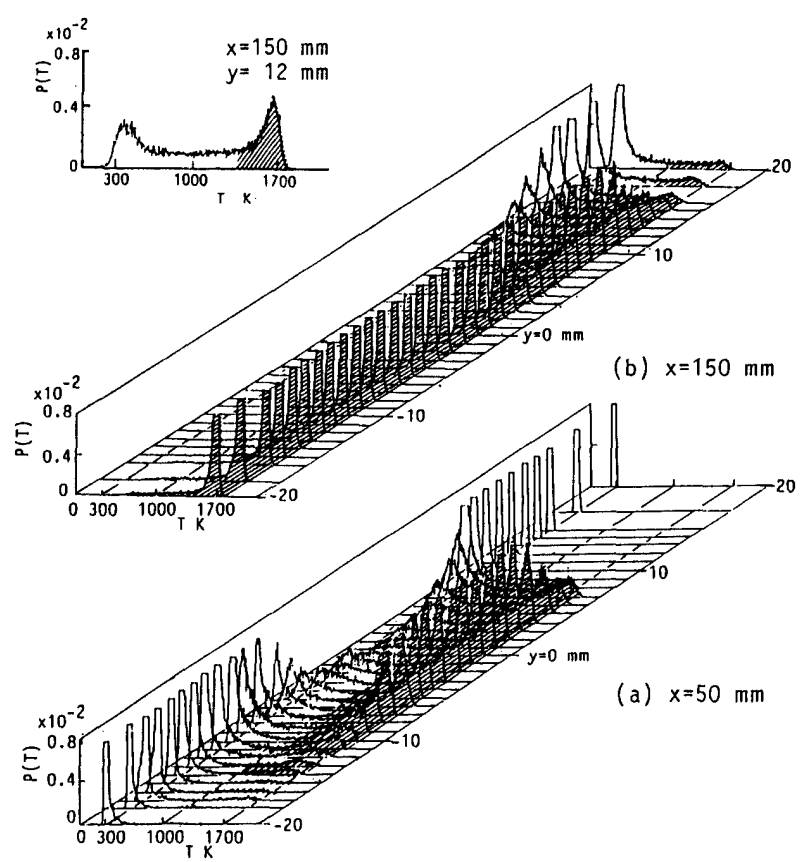

Fig. 8 Probability density functions of fluctuating temperature for $\Phi_{m}=0.6$

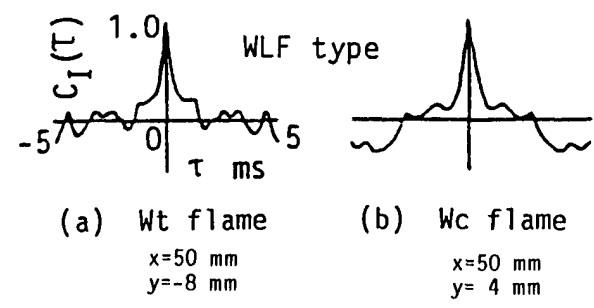

ion currents are studied to determine the concentration of reactions.

\section{4 Ion-current signals}

Since Karlovitz et al. first applied an electrostatic probe in studying the behavior of a turbulent flame $e^{(14)}$, it has been used by many investigators in their turbulent flame studies ${ }^{(15),(16)}$. However, very few examples of applying an electrostatic probe to a distributed reaction zone flame are found, except for the report of Summerfield et al. ${ }^{(17)}$ which discussed the special features of the ion-current signals.

In order to discuss the similarity or difference between the flames in a lean condition and those in intense turbulence, the ion-current signals are compared for the flames listed in Table 1. They are the present low Damkohler number flame in lean condition (Fig. 4(e ); to be represented as Dc) and a typical high Damkohler number propagating flame (Fig. $4(\mathrm{~g})$; to be represented as Wc), and the other two are an ordinary turbulent flame, $\mathrm{Wt}$, and a strongly turbulent flame, $\mathrm{Dt}$, in a shear layer ${ }^{(2)}$.

The ion-current signals were monitored at the middle of the reacting zone in the representative cross sections where flames which resembled a wrinkled laminar flame (WLF) or a distributed reaction zone flame (DRZ) were observed. Figure 9 shows the autocorrelation coefficients of ion-current signals for these flames. The autocorrelations for WLF's have a sharp and high peak at $\tau=0$ accompanied by a pair of low peaks (or periodically descending subpeaks) on both sides. This correlation pattern is compatible with the wrinkled laminar flame structure if we assume that the width of the sharp peak corresponds to the flame-zone thickness and the interval between peaks corresponds to the period of flame wrinkling. The $\tau$ value for the sharp peak descending to $1 / e$ is $0.38 \mathrm{~ms}$

Table 1 Experimental conditions

\begin{tabular}{|c|c|c|c|c|c|c|}
\hline Flame & \multicolumn{2}{|c|}{ Position } & $u^{\prime} \mathrm{m} / \mathrm{s}$ & $\phi_{m}$ & $\phi_{p}$ & Remarks \\
\hline & & & & & & \\
\hline$w_{t}$ & 100 & -8 & 0.15 & 0.65 & 0.6 & Ref.2(Run II-c) \\
\hline$D_{t}$ & 25 & 4 & 4.3 & 0.65 & 0.6 & Ref.2(Run III-c) \\
\hline$W_{c}$ & 50 & 4 & 0.54 & 0.6 & 0.6 & Present study \\
\hline$D_{c}$ & 50 & 4 & 0.54 & 0.4 & 1.0 & Present study \\
\hline
\end{tabular}

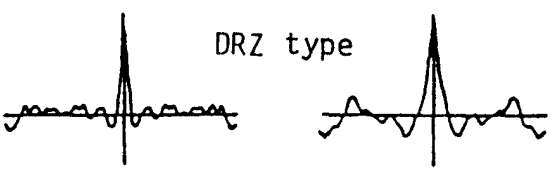
(c) Dt flame $x=25 \mathrm{~mm}$
$y=4 \mathrm{~mm}$
(d) DC flame $x=50 \mathrm{~mm}$ $y=4 \mathrm{~mm}$

Fig. 9 Autocorrelations for ion-current signals 
for Wt flame and $0.47 \mathrm{~ms}$ for Wc flame. These time spans multiplied by the stream velocity (about 10 $\mathrm{m} / \mathrm{s}$ ) give a length scale approximately $4 \mathrm{~mm}$. This scale is reasonable as the flame-zone thickness if it is considered that oblique flame elements whose width is expanded by turbulence reach the electrostatic needle which is as long as $0.5 \mathrm{~mm}$. In addition, the interval between the peaks is 1 to $1.5 \mathrm{~ms}$, which gives a length scale of 10 to $15 \mathrm{~mm}$ if it is multiplied by the stream velocity. This scale is not unrealistic as the period of flame wrinkling as far as the schlieren pictures in Fig. 2 of Ref. (2) are concerned.

In the autocorrelations for DRZ's, on the other hand, a single peak appears at $\tau=0$, unaccompanied by lower peaks on either side. This fact implies that the flame has no periodic structure such as does a wrinkled laminar flame and that small-scale reaction zones are randomly dispersed. The $\tau$-value for the peak descending to $1 / e$ is $0.22 \mathrm{~ms}$ for $\mathrm{Dt}$ flame and $0.46 \mathrm{~ms}$ for Dc flame, which corresponds to length scales of $2.2 \mathrm{~mm}$ and $4.6 \mathrm{~mm}$, respectively. These scales are taken to be the mean size of the reaction zone if it is assumed that the center of the reaction zone does not always pass the electrostatic needle which is as long as $0.5 \mathrm{~mm}$. They are close to the observed Taylor's microscale of turbulence, 3.0 to 5.7 $\mathrm{mm}$.

\subsection{Radical chemiluminescence}

Since the chemiluminescences of $\mathrm{C}_{2}-, \mathrm{CH}^{-}$and $\mathrm{OH}$-radicals i.e., the intermediates in combustion reactions, appear in this order, the detection of their presence is effective in identifying the reaction $z{ }^{(18)}$. In addition, it is also possible to estimate the rate of progress of the overall combustion reaction or to deduce the flame structure from the correlations between these signals. Therefore, the chemiluminescence signals of these radicals were monitored simultaneously, and analyzed statistically or spectrally ${ }^{(19)}$.

The intensity of $\mathrm{OH}$-chemiluminescence can be used as an index of overall reaction, except for extremely high-temperature flames, and is related not to their own concentration but to that of $\mathrm{CH}$-radicals because the step reaction to produce excited-state $\mathrm{OH}_{-}$ radicals is limited by the concentration of minor $\mathrm{CH}^{-}$ radicals. Further, $\mathrm{CH}$-emission is detected at the initial stage of hydrocarbon combustion, and its intensity is proportional to the $C_{2}$ concentration. Simultaneous measurements of these three radicals and their statistical analyses were carried out. Care must be taken in interpreting the chemiluminescence signals, since the space resolution of the signals, which are integrated over the optical path, is poor and the control volumes for different radicals do not always coincide with each other.

Figure 10 shows the autocorrelation coefficients of $\mathrm{OH}$ emissions for the flames. The autocorrelations for WLF's have a pair of symmetrical peaks on both sides of the peak centered at $\tau=0$. In contrast, no such pair is seen in DRZ's. The features are consistent with those of ion current in Fig. 7.

Figure 11 shows the cross-correlations between $\mathrm{OH}^{-}$and $\mathrm{C}_{2}$-radical emissions for four kinds of flame. It is common to all flames that a peak appears at $\tau=0$. It is one evidence of hydrocarbon combustion that $\mathrm{CH}^{-}$and $\mathrm{C}_{2}$-radicals fluctuate synchronously.

Figure 12 shows the cross-correlations between $\mathrm{OH}^{-}$and $\mathrm{CH}$-radical emissions for four kinds of flame. In WLF'S it is conjectured that the combustion reactions are confined in a relatively narrow zone because the cross-correlations in ( $a$ ) and ( $b$ ) have a
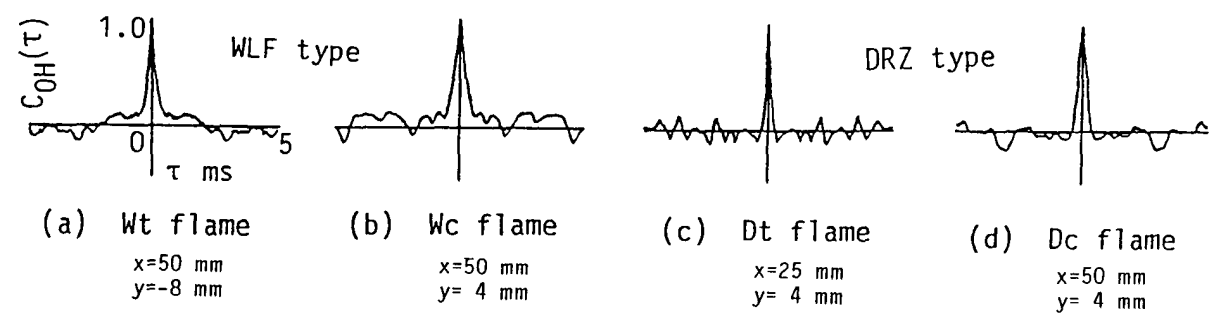

Fig. 10 Autocorrelations for $\mathrm{OH}$-band emissions

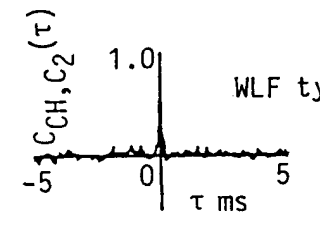

(a) Wt flame $x=50 \mathrm{~mm}$
$y=-8 \mathrm{~mm}$

Fig. 11 Cross-correlations between $\mathrm{CH}^{-}$and $\mathrm{C}_{2}$-band emissions

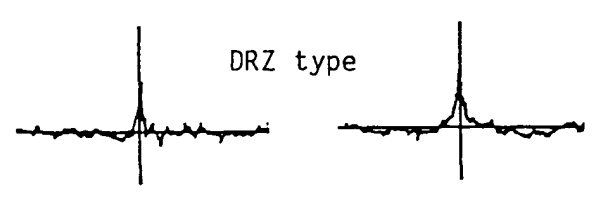
(c) Dt flame $x=25 \mathrm{~mm}$ $x=25 \mathrm{~mm}$
$y=4 \mathrm{~mm}$ $x=50 \mathrm{~mm}$ $y=4 \mathrm{~mm}$




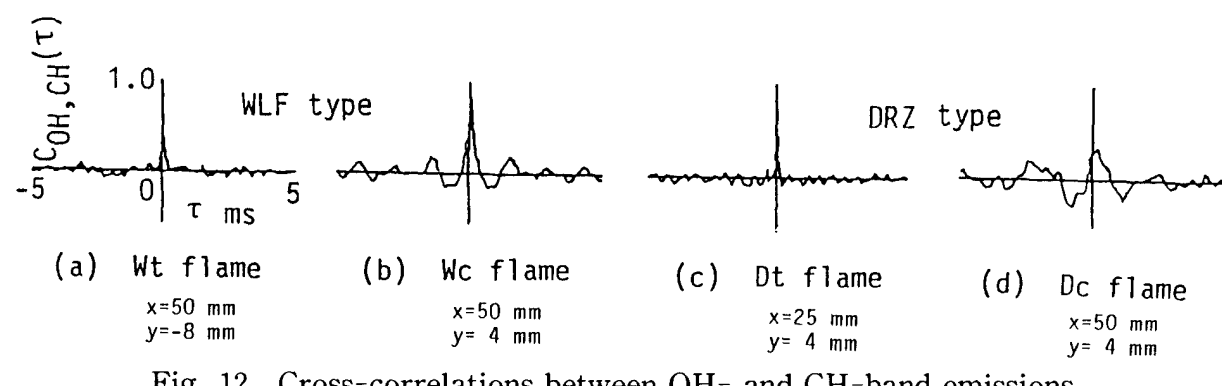

Fig. 12 Cross-correlations between $\mathrm{OH}^{-}$and $\mathrm{CH}-$ band emissions

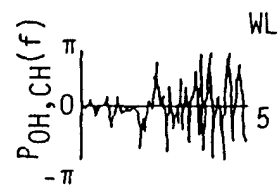

(a) Wt flame $x=50 \mathrm{~mm}$
$y=-8 \mathrm{~mm}$
WLF type

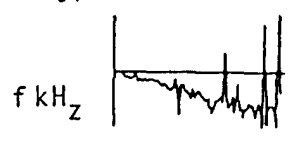

(b) Wc flame

$x=50 \mathrm{~mm}$
$y=4 \mathrm{~mm}$

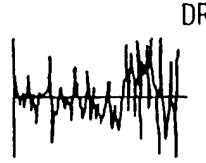

(c) Dt flame $x=25 \mathrm{~mm}$
$y=4 \mathrm{~mm}$
DRZ type

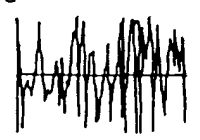

(d) DC flame $x=50 \mathrm{~mm}$
$y=4 \mathrm{~mm}$

Fig. 13 Phase between $\mathrm{OH}-$ and $\mathrm{CH}^{-}$band emissions

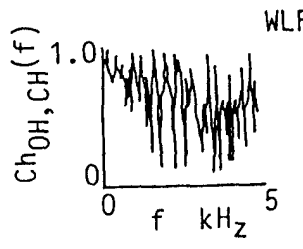

(a) Wt flame $x=50 \mathrm{~mm}$ $y=-8 \mathrm{~mm}$
WLF type

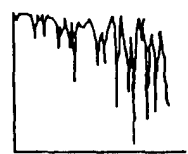

(b) Wc flame $x=50 \mathrm{~mm}$
$y=4 \mathrm{~mm}$

Fig. 14 Coherences between $\mathrm{OH}-$ and $\mathrm{CH}$-band emissions

peak at $\tau=0$, hence the similarity in the behavior of $\mathrm{OH}^{-}$and $\mathrm{CH}$-radicals. On the other hand, the peaks at $\tau=0$ in (c) and (d) for DRZ's decrease in height, and the correlation between the two signals becomes less significant. The reactions in DRZ flames are not concentrated in a thin interface but are randomly dispersed.

Figures 13 and 14 show the phase (phase difference) and coherence (cross-correlation in frequency domain), respectively, between $\mathrm{OH}-$ and $\mathrm{CH}^{-}$ radical emissions. The abscissa is the Fourier frequency, $f[\mathrm{kHz}]$. Generally speaking, the phase and coherence fluctuate around 0 radians and unity, respectively, which is characteristic of premixed flames. The phase and coherence for WLF's shown in Figs. 13(a) and (b), and 14(a) and (b) are close to 0 radians and unity, respectively, at least in the lowfrequency region. If the signals contain emissions from the flames before and after the control volume, as well as background noise, the features above imply that the flame consists of thin laminar flames/ flamelets. In contrast, the phase and coherence for DRZ's shown in Figs. 13(c) and (d), and 14(c) and (d) fluctuate violently even in the low-frequency region, and the coherence is far lower than that for WLF's. This implies that the reaction zones where the chemiluminescences of $\mathrm{OH}^{-}$and $\mathrm{CH}$-radicals do not coincide in time and space are randomly dispersed.

The phase for Wc flame in Fig. 13(b) decreases linearly from 0 radians with frequency. This suggests that $\mathrm{CH}$-radical emission precedes $\mathrm{OH}$-radical emission by a fixed time interval. This advance is estimated to be about $80 \mu \mathrm{s}$ from the gradient. It is not clear, however, whether this advance corresponds to the order in reaction timing.

Summarizing the results described above, we can conclude that the structure of a lean flame below the flammability limit supported by a high-temperature pilot has the same features as those of the distributed reaction zone in intense turbulence.

\section{Conclusions}

We examined the detailed structure of the turbulent flames with weak reactivity, which were stabilized by a pilot burner in a uniform shear flow of lean combustible mixture. The conclusions obtained are as follows.

(1) A flame is formed in the turbulent mixing layer between a hot-burnt gas and a lean combustible mixture even if the mixture strength is below the lean flammability limit. As the equivalence ratio is increased, this flame varies from one similar to a 
so-called "distributed reaction zone flame" into an ordinary "wrinkled laminar flame."

(2) The results of the statistical and spectral analyses of temperature, ion current and radical chemiluminescence signals for this lean flame are similar to those for an ordinary turbulent flame stabilized in intense turbulence. Therefore, it is considered that the lean turbulent flame near extinction is the same as a distributed reaction zone flame exposed to intense turbulence, and that a distributed reaction zone flame is a flame which has almost lost its ability to propagate.

\section{References}

(1) Katsuki, M., Mizutani, Y., Yasuda, T., Kurosawa, Y., Kobayashi, K. and Takahashi, T., The Effect of Initial Conditions on the Propagation of a Premixed Flame in a Mixing Layer, Combust. Flame, Vol. 74, No. 1(1988), p. 9.

(2) Katsuki, M., Mizutani, Y., Yasuda, T., Kurosawa, Y., Kobayashi, K. and Takahashi, T., Local Fine Structure and its Influence on Mixing Processes in Turbulent Premixed Flames, Combust. Flame, Vol. 82, No. 1(1990), p. 93.

(3) Furukawa, J., Harada, E. and Hirano, T., Microstructure of High-Intensity Turbulent Premixed Flame, Trans. Jpn. Soc. Mech. Eng., (in Japanese), Vol. 55, No. 520, B(1989), p. 3758.

(4) Yoshida, A., Structure of Opposed Jet Premixed Flame and Transition of Turbulent Premixed Flame Structure, 22nd Symp. (Int.) on Combust., (1988), p. 1471, The Combustion Institute.

(5) Damkohler, G., The Effect of Turbulence on the Flame Velocity in Gas Mixtures, NACA TM1112, (English trans.), (1974).

(6) Masri, A.R., Dibble, R.W. and Bilger, R.W., Turbulent Nonpremixed Flames of Methane Near Extinction: Mean Structure from Raman Measurements, Combust. Flame, Vol.71, No. 3(1988), p. 245 .

( 7 ) Magre, P. and Dibble, R.W., Fine Chemical Kinetic Effects in a Subsonic Turbulent Hydrogen Flame, Combust. Flame, Vol.73, No. 2(1988), p. 195.

( 8 ) Masri, A.R., Bilger, R.W. and Dibble, R.W., Turbulent Nonpremixed Flames of Methane Near
Extinction: Probability Density Functions, Combust. Flame, Vol.73, No. 3(1988), p. 261.

(9) Mungal, M.G., Dimotakis, P.E. and Broadwell, J. E., Turbulent Mixing and Combustion in a Reacting Shear Layer, AIAA J., Vol. 22, No. 6(1984), p. 797.

(10) Mungal, M.G. and Dimotakis, P.E., Mixing and Combustion with Low Heat Release in a Turbulent Shear Layer, J. Fluid Mech., Vol. 148, (1984), p. 349 .

(11) Mungal, M.G. and Frieler, C.E., The Effects of Damkohler Number in a Turbulent Shear Layer, Combust. Flame, Vol. 71, No. 1(1988), p. 23.

(12) Katsuki, M., Mizutani, Y. and Matsumoto, Y., An Improved Thermocouple Technique for Measurement of Fluctuating Temperatures in Flames, Combust. Flame, Vol. 67, No. 1(1987), p. 27.

(13) Tsuji, H., Counterflow Diffusion Flames, Prog. Energy Combust. Sci., Vol. 8, No. 2(1982), p. 93.

(14) Karlovitz, B., Denniston Jr., D.W., Knapschaefer, D.H. and Wells, F.E., A. Flame Propagation across Velocity Gradients: B. Turbulence Measurement in Flames, 4th Symposium (Int.) on Combustion, (1953), p. 613, The Combustion Institute.

(15) Suzuki, T., Hashimoto, Y., Mashiko, I. and Hirano, T., Ion-Current Fluctuations Recorded with a Cylindrical Electrostatic Probe Passing Premixed Flames, Combust. Flame, Vol. 36, No. 2(1979), p. 179.

(16) Ventura, J.M.P., Suzuki, T. and Yule, A.J., The Investigation of Time Dependent Flame Structure by Ionization Probes, 18th Symposium (Int.) on Combustion, (1981), p. 1543, The Combustion Institute.

(17) Summerfield, M., Reiter, S.H., Kebely, V. and Mascolo, R.W., The Structure and Propagation Mechanism of Turbulent Flames in High Speed Flow, Jet Propulsion, Vol. 25, No. 8(1955), p. 377.

(18) Mizutani, Y., Saeki, T. and Nakabe, K., Processing of Luminescent Radical Images for Flame Diagnostics, JSME Int. J., Ser.II, Vol. 32, No. 3(1989), p. 455.

(19) Nakabe, K., Mizutani, Y., Hirao, T. and Fujioka, H., An Experimental Study on Detailed Flame Structure of Liquid Fuel Sprays with/without Gaseous Fuel, Combust. Flame, Vol. 84, No. 1(1991), p. 3. 